\title{
The Mediator Role of Communication about COVID-19 on the Relationship between Exaggeration of Media and Generated Fear: Case of North Cyprus
}

\author{
Aysen Berberoglu ${ }^{1}$, Asım Dinler ${ }^{2}$
}

\author{
${ }^{1}$ University of Mediterranean \\ Karpasia, North Cyprus, Turkey \\ ${ }^{2}$ American University of Cyprus, \\ North Cyprus, Turkey
}

Correspondence:

Aysen Berberoglu

Address: University of Mediterranean Karpasia, North Cyprus, Turkey

Email: aysen.berberoglu@gmail.com
Received: 24.06.2020,

Accepted: 12.08 .2020

https://doi.org/10.29333/jcei/9281

\begin{abstract}
In the first half of 2020 the world population was hit by a Novel Coronavirus outbreak that leads to severe acute respiratory syndrome, which later named as COVID-19. The countries soon started to report their first cases and in March the COVID-19 which was initially declared as a public health emergency then later declared as a pandemic by World Health Organization (WHO). The fear generated as a result of the pandemic among the people has many antecedents. The aim of this study was to find out the hypothesized relationship between the generated fear and the exaggeration of the media about pandemic, as well as to look at whether communication from health professionals, family and friends mediates this relationship. According to the results of the analysis which has been carried out by the data collected by questionnaire, there is a positive and strong relationship between all three variables. Additionally, mediation analysis showed that the relationship between exaggeration of media and generation of fear is mediated by the communication by health professionals, friends and family meaning that communication plays an important role in terms of generated fear.
\end{abstract}

Keywords: media, COVID-19, fear, communication

\section{INTRODUCTION}

In the first half of 2020 the world population was hit by a Novel Coronavirus outbreak that leads to severe acute respiratory syndrome, which later named as COVID-19. It was first emerged in Wuhan city of China presumably at the end of 2019 however spread widely starting from January 2020 and peaked in February. Unfortunately, the peak of the outbreak in China was just a starting point for a worldwide pandemic. The countries soon started to report their first cases and in March the COVID-19 which was initially declared as a public health emergency then later declared as a pandemic by World Health Organization [1].

COVID-19 pandemic is one of the biggest pandemics the world has faced in the current century and it is not difficult to anticipate the negative effects on the society besides the health problems. One of the problems COVID-19 pandemic and the quarantines and restrictions which are the consequences of the pandemic brought about to the people is the psychological disturbances more specifically "fear".

The fear generated as a result of the pandemic among the people has many antecedents. The aim of this study was to find out the hypothesized relationship between the generated fear and the exaggeration of the media about pandemic, as well as to look at whether communication from health professionals, family and friends mediates this relationship.

The study is important because it is currently the first study trying to evaluate the relationship between the generated fear and the exaggeration of the media about pandemic, as well as to understand whether communication from health professionals, family and friends mediates this relationship. Additionally, the study is specifically looking at the perceptions of people who are residing in North Cyprus 
helping to understand how pandemic affected the people in North Cyprus as a result of the media coverage and communication of the society.

The research is trying to answer the research questions below:

- Does exaggeration of media have a relationship with generated fear about pandemic?

- Does the communication from health professionals, family and friends mediates the hypothesized relationship between exaggeration of media and generated fear?

Hypothesis for the current study are:

H1: There is a relationship between Exaggeration of Media and communication

H2: There is a relationship between communication and generated fear

H3: There is a relationship between exaggeration of media and generated fear

H4: The Relationship between exaggeration of media and generated fear is mediated by communication

The current project firstly will present a review of the literature about the three variables adopted in the study which are exaggeration of media, communication from health professionals, family and friends and generated fear. In the current research study, exaggeration of media represents the independent variable, communication from health professionals, family and friends is the mediating variable and generated fear is the dependent variable.

Secondly, the project will present the methodology information including the method used to collect data, data instrument, population and sample of the study.

Later analysis and results will be presented. Lastly a conclusion will be drawn from the analysis which has been carried out. Also, there will be limitations and suggestion for future research in the last part of the project.

\section{LITERATURE REVIEW}

In the current situation even though $60 \%$ of the world's population is located in Asia and 17\% in Africa, the leading continents in terms of Covid-19 cases are Europe with $45 \%$ and N. America with 34\%, so it is possible to say that Covid19 does not spread evenly compared to the world population and it has a spread widely especially in Europe and North America [2].

In the spread of pandemic late-onset countries benefited from the experiences of earlier onset countries and implemented measures in order to protect their people however, the cases and deaths could not be prevented. It is possible to say that the process of the pandemic varied according to country-specific dynamics [3].
The spread of the pandemic has caused lots of damage to the people of the world interrupted their lives in various dimensions; health, economic and social effects.

\section{Media}

The concept of media, which we also call mass media, has been used since the 1920s [4].

The most important form of organization of the mass communication process is the media [5]. The media is briefly "the name given to the masses by sending messages to the masses, informing them about the events, providing mass communication tools such as newspapers, magazines, TV, radio, and the internet that can create platforms for discussion on social problems" [6].

According to Daniel Katz, Graeme Burton and Denis McQuail, the media has five main functions. These are 1. Information, 2. Cultural continuity, 3. Socialization, 4. Creating public opinion, and 5. Entertaining [7]. With the capitalist understanding of production, the media has changed rapidly in the pursuit of commercial success and has taken on a structure that serves mass culture with programs whose primary function is to satisfy economic interests [8].

When media tries to set the spotlight of the news there are some inevitable actions it takes like:

- Media tries to keep the events alive by processing different types of information and by drawing attention

- Media uses a language that will affect the perception of the importance of the subject.

It is important to catch the opinions when well-known and reliable people start talking about a topic, so the spotlight is created

- Spotlight setting may not be the same for all individuals in the same scope and in the same way.

The role of well-known people who comment on the subject is an important factor for setting up the spotlight [9].

One of the forces that influence the media's agenda is the content of the other media. Especially, the agenda of famous printed media is an important factor. Sometimes, printed media goes in front of television channels. There are some factors that affect the content of the media[10].

There are some factors that affect the content of the media [10].

1- Effects caused by media workers which include the characteristics, personal and professional accumulation, personal attitudes and professional roles of employees in the field of communication.

2- Effects caused by media monotonous including time constraints, requirements in the broadcast, structure of news writing, news values, the standard of objectivity, and reporters' commitment to official sources. 
3- Organizational effects on content which is affected by the fact that media organizations have primary goals. Making money is necessary as for every organization. These can have numerous effects on content.

4- Effects emerging from outside the media organizations include interest groups lobbying for a certain content (may also be the opposite lobby), making artificial events to be covered by the media or directly regulating the content.

5- The effect of ideology like the ideological attitudes and fluctuations of the society directly reflect on the content of the media.

\section{Exaggeration of Media, Generated Fear and Social Communication}

The most important product of the media is the "news" [11]. In order to attract the attention of the audience and keep the attention it is possible for media organizations to make semi-real constructions by mixing the real with the imaginary situations [12]. That's why it is safe to say that news is not always the truth [13].

Today's popular social media networks, youtube, twitter, facebook and instagram, have made it easier to access unlimited and suspicious information thanks to the masses it can reach. In line with the infrastructure of social networks, algorithms allow the content, i.e., information, to be disseminated simultaneously [14].

Societies constantly encounter problems within certain periods of time like what has happened in COVID-19 pandemic. Media organizations report on these problems and include their comments and opinions. When problems are constantly processed by the media leads to a search for solutions to the problem and the demands of the readers and the audience to raise. A state of fear and anxiety arising from this event covers the society and leads to a panic [15].

Fear or concern is defined as a narrated behavior or event triggers anxiety [16].

The first research on the influence of media on people's fears was done by Gerbner et al. The "cultural indicators project", which started in the 1960s consists of three sections: institutional analysis, message system analysis and training analysis. Institutional analysis reveals the formation of policies that govern the mass flow of media messages; analysis of the message system, to describe the trends and features offered by the television world to its audience; analysis aims to examine the effect of television on people's thoughts about social reality. At the end of the project, it was determined that there were mostly violent news on television programs in the main broadcast zone. Exposure to television violence plays an important role in people's perception of social reality [17].

In social media during the COVID-19 pandemic there are lots of alarming video clips in circulation which can be easily disseminated and accessed by all individuals through phones, computers and tablets [18].

In the current technology there are algorithms on social media which can block video clips from being uploaded which is harmful and can create panic among the general public (India's Internet shutdown in Kashmir is the longest ever in a democracy, 2020, Washington Post, 2020). However this was not helpful during COVID-19 pandemic because the videos did not really include any material which is categorized harmful (including blood or dangerous tools) but only images of sick people, creepy healthcare professionals and bags of dead bodies that was already enough to generate fear.

To the best of our knowledge, this is the first investigation of the mental health impacts of COVID-19 experiences during the 2020 coronavirus pandemic and national lockdown in South Africa. We report that the relationship between increased depressive symptoms and greater perceived COVID-19 infection risk was more severe among adults who reported worse histories of childhood trauma. Adults were two times more likely to experience significant depressive symptoms for every one unit increase in perceived COVID-19 risk. Greater knowledge of COVID-19 prevention and transmission was associated with lower perceived risk of depression but higher depressive symptoms. While a large majority of participants reported that experiences of the COVID-19 pandemic did not affect their mental health (or "mind"), 10-20\% of participants reported potent experiences of anxiety, fear, and "thinking too much" as a result of the pandemic. Our results highlight the compounding effects of past traumatic histories and recent stress exposures on exacerbating the severity of depressive symptoms among adults living in an urban South African context [19].

In a research within a recent study a low level of positive correlation was found between state anxiety levels and psychological performance levels of amateur footballers. The fact that amateur footballers lose their physical and psychological performance levels, both in pre-season preparation camps and during the league, until they start their pandemic process, and because they cannot find enough training and working opportunities for competitions that will start again in this last period of the pandemic process, they cannot show the desired performances. It is thought that they were caused by thinking that they might have concerns [20].

According to the data obtained from another recent literature state that anxiety levels of the women were found higher than men as a result of the pandemic situation. Exercise during coronavirus pandemic is thought to affect individual's mental health in positive way according to the obtained data. As one of the Coronavirus risk factors, smoking was shown to have no significant effect on participants' anxiety levels [21]. 
According to the existing literature, common categories of fear that is generated as a response to the COVID-19 pandemic are as follows

- possible negative impact on household finances generates fear

- possible unavailability or lack of health care services generates fear

- fear of insufficiency in food supply.

Furthermore, a recent study carried out in Czech Republic found out that the communication used by Czech media during the COVID-19 pandemic is a significant incident of a traumatizing form of media communication during an outbreak. The "bad ending stories" contributed negatively to the psychological situation of the Czech population along with the negative tone of the messages during the COVID-19 pandemic. This intended by an effort to reach the most audience as much as possible. The behavior media and the key role of journalists and media officials is very important in terms of influencing the well-being of the general public during the times of uncertainty and fear [23].

After the first positive case of COVID-19 in North Cyprus, people started to feel the fear on elevated levels. People in North Cyprus utilized social media to disseminate latest information about COVID-19 where they gathered in and they encouraged everyone to stay at home and stay safe. However the main reason for the fear generated by Turkish Cypriots was not about the information shared on social platforms but was about the perceived weakness of healthcare system in North Cyprus because people were insecure about the current healthcare system [24].

\section{METHODOLOGY}

\section{Population and Sample Size}

The population of the study was the people living in Northern Cyprus during COVID-19 pandemic. Since it is not possible to determine the exact population, researcher tried to reach as much respondents as possible within a limited time period. Sample size was calculated with $8.31 \%$ margin of error and $90 \%$ confidence level and turned out to be 98 respondents.

\section{Data Collection Method and Instrument}

The study adopted a quantitative approach. Data was collected with the help of an online questionnaire. Respondents were asked to fill in the questionnaires by themselves online with the help of Google Forms. The questionnaires were distributed mainly on social media pages related to COVID-19.

Questionnaire was made up of two main parts. The first part of the survey included demographic questions like gender, age, education level and occupation. Second part of the questionnaire included statements regarding three variables of the study that are measured with 5-point Likert scale. The variables were as follows:

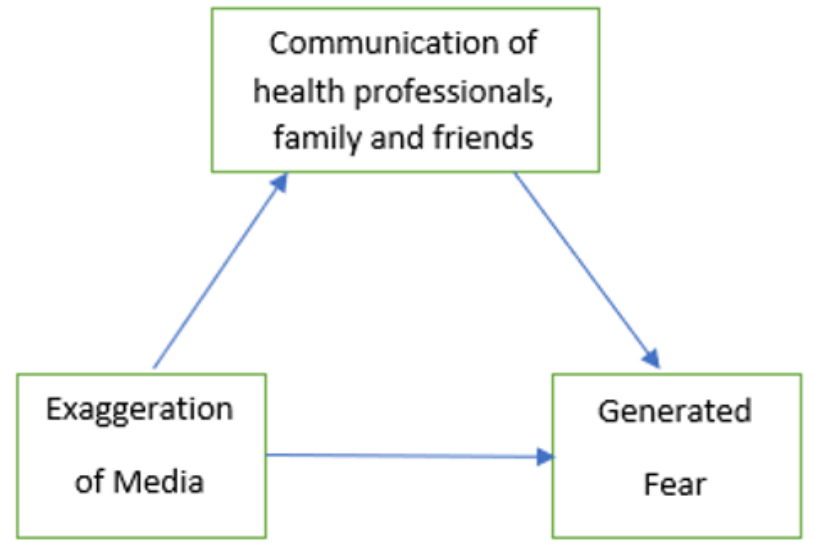

Figure 1. Model of the Study

- Exaggeration of Media (Inependent variable)

- Communication (Mediator variable)

- Generated Fear (Dependent variable)

The questionnaire was adopted from the recent study of Mejia et al. (2020) named as "The Media and their Informative Role in the Face of the Coronavirus Disease 2019 (COVID-19): Validation of Fear Perception and Magnitude of the Issue (MED-COVID-19)".

The questions from 1-4 was about the "Exaggeration of Media" about COVID-19 pandemic as follows:

1. "Television is exaggerating the issue"

2. "Social media are exaggerating the issue"

3. "Magazines/newspapers are exaggerating the issue"

4. "The radio is exaggerating the issue"

The questions from 5-8 was about the "Generated Fear" about COVID-19 pandemic as follows:

1. "Television makes me very afraid"

2. "Social media make me very afraid"

3. "Magazines/newspapers make me very afraid"

4. "The radio makes me very afraid"

The questions from 5-8 was about the "Communication from health professionals, family and friends" about COVID-19 pandemic as follows:

1. "Physicians and health personnel are exaggerating the issue"

2. "Physicians and health personnel make me very afraid"

3. "My family/friends are the ones who are exaggerating the issue"

4. "My family/friends make me very afraid"

Model and Hypothesis

The model of the study was constructed as shown in Figure 1.

According to the model below hypothesis were constructed:

H1: There is a relationship between Exaggeration of Media and communication 
The Mediator Role of Communication about COVID-19 on the Relationship between Exaggeration of Media and Generated Fear

Table 1. Reliability Statistics of Exaggeration of Media

\begin{tabular}{cc}
\hline Cronbach's Alpha & N of Items \\
\hline .899 & 4 \\
\hline
\end{tabular}

Table 2. Reliability Statistics of Generated Fear

\begin{tabular}{cc}
\hline Cronbach's Alpha & N of Items \\
\hline .935 & 4 \\
\hline
\end{tabular}

Table 3. Reliability Statistics of Communication

\begin{tabular}{cc}
\hline Cronbach's Alpha & N of Items \\
\hline .804 & 4 \\
\hline
\end{tabular}

Table 4. Gender

\begin{tabular}{cccccc}
\hline & & Frequency & Percent & $\begin{array}{c}\text { Valid } \\
\text { Percent }\end{array}$ & $\begin{array}{c}\text { Cumulative } \\
\text { Percent }\end{array}$ \\
\hline \multirow{3}{*}{ Valid } & Female & 74 & 67.3 & 67.3 & 67.3 \\
\cline { 2 - 6 } & Male & 36 & 32.7 & 32.7 & 100.0 \\
\cline { 2 - 6 } & Total & 110 & 100.0 & 100.0 & \\
\hline
\end{tabular}

Table 5. Age

\begin{tabular}{cccccc}
\hline & Frequency Percent & $\begin{array}{c}\text { Valid } \\
\text { Percent }\end{array}$ & $\begin{array}{c}\text { Cumulative } \\
\text { Percent }\end{array}$ \\
\hline \multirow{2}{*}{ Valid } & 35 & 31.8 & 31.8 & 31.8 \\
\cline { 2 - 6 } & $40-28$ & 47 & 42.7 & 42.7 & 74.5 \\
\cline { 2 - 6 } & $51-61$ & 8 & 7.3 & 7.3 & 90.9 \\
\cline { 2 - 6 } Above 61 & 2 & 1.8 & 1.8 & 100.0 \\
\cline { 2 - 6 } & Total & 110 & 100.0 & 100.0 & \\
\hline
\end{tabular}

H2: There is a relationship between communication and generated fear

H3: There is a relationship between exaggeration of media and generated fear

H4: The Relationship between exaggeration of media and generated fear is mediated by communication

\section{ANALYSIS AND FINDINGS}

\section{Reliability Analysis}

\section{Exaggeration of media}

According to the results of first reliability analysis, the exaggeration of media variable has a high level of reliability (Cronbach's Alpha value 0.899).

\section{Generated fear}

The generated fear variable has a high level of reliability (Cronbach's Alpha value 0.935) according to the results of second reliability analysis.

\section{Communication}

Table 6. Education

\begin{tabular}{|c|c|c|c|c|c|}
\hline & & Frequency & Percent & $\begin{array}{l}\text { Valid } \\
\text { Percent }\end{array}$ & $\begin{array}{c}\text { Cumulative } \\
\text { Percent }\end{array}$ \\
\hline \multirow{7}{*}{ Valid } & Primary School & 2 & 1.8 & 1.8 & 1.8 \\
\hline & $\begin{array}{l}\text { Middle } \\
\text { School }\end{array}$ & 1 & .9 & .9 & 2.7 \\
\hline & $\begin{array}{l}\text { High } \\
\text { School }\end{array}$ & 14 & 12.7 & 12.7 & 15.5 \\
\hline & $\begin{array}{c}\text { Bachelor } \\
\text { Degree }\end{array}$ & 46 & 41.8 & 41.8 & 57.3 \\
\hline & Master Degree & 29 & 26.4 & 26.4 & 83.6 \\
\hline & $\begin{array}{c}\text { PhD } \\
\text { Degree }\end{array}$ & 18 & 16.4 & 16.4 & 100.0 \\
\hline & Total & 110 & 100.0 & 100.0 & \\
\hline
\end{tabular}

Table 7. Occupation

\begin{tabular}{|c|c|c|c|c|c|}
\hline & & Frequency & Percent & $\begin{array}{l}\text { Valid } \\
\text { Percent }\end{array}$ & $\begin{array}{c}\text { Cumulative } \\
\text { Percent }\end{array}$ \\
\hline \multirow{7}{*}{ Valid } & Health Worker & 7 & 6.4 & 6.8 & 6.8 \\
\hline & $\begin{array}{c}\text { Academician/ } \\
\text { Teacher }\end{array}$ & 20 & 18.2 & 19.4 & 26.2 \\
\hline & $\begin{array}{l}\text { Entrepreneur / } \\
\text { Business Person }\end{array}$ & 9 & 8.2 & 8.7 & 35.0 \\
\hline & $\begin{array}{l}\text { Media Worker } \\
\text { (Newspaper / } \\
\text { Radio / TV etc.) }\end{array}$ & 1 & .9 & 1.0 & 35.9 \\
\hline & Private Sector & 36 & 32.7 & 35.0 & 70.9 \\
\hline & Other & 30 & 27.3 & 29.1 & 100.0 \\
\hline & Total & 103 & 93.6 & 100.0 & \\
\hline \multirow[t]{2}{*}{ Missing } & System & 7 & 6.4 & & \\
\hline & Total & 110 & 100.0 & & \\
\hline
\end{tabular}

According to the results of last reliability analysis, the communication from health professionals, family and friends variable also has a relatively high level of reliability (Cronbach's Alpha value 0.804).

\section{Demographic variables}

The respondents of the study were $67.3 \%$ females and $32.7 \%$ males.

The majority of the respondents found to be between age of 29 and 39 (42.7\%). Respondents between 18-28 years of age were $31.8 \%$ of the sample. Respondents between $40-50$ years of age accounted for $16.4 \%$ of the total and $7.3 \%$ of the respondent had age of between 51-61. Only $1.8 \%$ of the respondents were above 61 years.

The majority of the respondents found to be bachelor's degree graduates (41.8\%). Total of Master and $\mathrm{PhD}$ degree holders account for the $42.8 \%$ of the population while the remaining was high school graduate or lower degree (15.4\%).

The majority of the respondents were employed in the private sector (32.7\%). $18.2 \%$ of the sample accounted for the academicians/teachers and $6.4 \%$ were health sector workers. 
The Mediator Role of Communication about COVID-19 on the Relationship between Exaggeration of Media and Generated Fear

\begin{tabular}{|c|c|c|c|c|}
\hline & & Exaggeration of media & GeneratedFear & Communication \\
\hline & Pearson Correlation & 1 & $.539^{* *}$ & $.661^{* *}$ \\
\hline \multirow[t]{3}{*}{ Exaggeration of media } & Sig. (2-tailed) & & .000 & .000 \\
\hline & $\mathrm{N}$ & 110 & 110 & 110 \\
\hline & Pearson Correlation & $.539^{* *}$ & 1 & $.646^{* *}$ \\
\hline \multirow[t]{3}{*}{ Generated Fear } & Sig. (2-tailed) & .000 & & .000 \\
\hline & $\mathrm{N}$ & 110 & 110 & 110 \\
\hline & Pearson Correlation & $.661^{* *}$ & $.646^{* *}$ & 1 \\
\hline \multirow[t]{2}{*}{ Communication } & Sig. (2-tailed) & .000 & .000 & \\
\hline & $\mathrm{N}$ & 110 & 110 & 110 \\
\hline
\end{tabular}

**. Correlation is significant at the 0.01 level (2-tailed).

Table 9. Mediation Analysis 1

\begin{tabular}{|c|c|c|c|c|c|c|c|}
\hline Ooutcome Vari & & & & & & & \\
\hline Generate & & & & & & & \\
\hline \multicolumn{8}{|c|}{ Model Summary } \\
\hline & $\mathbf{R}$ & R-sq & MSE & $\mathbf{F}$ & df1 & df2 & $\mathbf{P}$ \\
\hline & .6611 & .4370 & .5835 & 83.8384 & 1.0000 & 108.0000 & .0000 \\
\hline \multicolumn{8}{|l|}{ Model } \\
\hline & & coeff & se & $t$ & $\mathbf{P}$ & LLCl & ULCI \\
\hline Constant & & 1.4118 & .2087 & 6.7655 & .0000 & .9981 & 1.8254 \\
\hline Exaggera & & .6400 & .0699 & 9.1563 & .0000 & .5014 & .7785 \\
\hline
\end{tabular}

8.2\% found to be business people and remaining $27.3 \%$ included other occupations (Housewife, Lawyer, Retired etc.). 7 of the respondents didn't want to declare their occupation or they are not employed.

\section{Correlation Analysis}

Correlation analysis was utilized in order to test the hypothesis regarding the relationship between three variables which are

- Exaggeration of Media (Independent variable)

- Communication (Mediator variable)

- Generated Fear (Dependent variable)

The hypothesis tested are as follows:

- H1: There is a relationship between Exaggeration of Media and communication

- H2: There is a relationship between communication and generated fear

- H3: There is a relationship between exaggeration of media and generated fear

According to Table 8 there is a positive and strong relationship between Exaggeration of Media and communication (.661). Also, the relationship between communication and generated fear is also found to be strong and positive (.646). Lastly the relationship between exaggeration of media and generated fear had a correlation value of .539 which can be accounted for a good level of correlation. According to the results of correlation analysis it is possible to conclude that hypothesis 1,2 and 3 is accepted.

\section{Mediation Analysis}

Mediation analysis was carried out in order to test the hypothesis 4

H4: The Relationship between exaggeration of media and generated fear is mediated by communication

When the results of regression are analyzed in Table 9, it is possible to say that the strength of the effect of exaggeration media variable on communication is 0.6400 .

When the results of second regression is analyzed it is possible to say that the strength of the effect of communication on generated fear variable is 0.5881 . Continuously, the strength of the effect of exaggeration of media on generated fear variable is 0.2194 .

Lastly, the proportion of total effect of exaggeration of media on generated fear that operates indirectly is found to be $63 \%$. 
The Mediator Role of Communication about COVID-19 on the Relationship between Exaggeration of Media and Generated Fear

\begin{tabular}{|c|c|c|c|c|c|c|c|}
\hline \multicolumn{8}{|c|}{ Ooutcome Variable } \\
\hline \multicolumn{8}{|l|}{ Generate } \\
\hline \multicolumn{8}{|c|}{ Model Summary } \\
\hline & $\mathbf{R}$ & R-sq & MSE & $\mathbf{F}$ & df1 & df2 & $\mathbf{P}$ \\
\hline & .6634 & .4401 & .7631 & 42.0534 & 2.0000 & 107.0000 & .0000 \\
\hline \multicolumn{8}{|l|}{ Model } \\
\hline & & coeff & se & $t$ & $\mathbf{P}$ & LLCI & ULCI \\
\hline Constant & & .3190 & .2847 & 1.1202 & .2651 & -.2455 & .8835 \\
\hline Exaggera & & .2194 & .1065 & 2.0594 & .0419 & .0082 & .4306 \\
\hline Communic & & .5881 & .1100 & 5.3440 & .0000 & .3699 & .8062 \\
\hline
\end{tabular}

Table 11. Mediation Analysis 3

\begin{tabular}{cccccccc}
\hline Total Effect of $\mathbf{X}$ on $\mathbf{Y}$ & \multicolumn{1}{c}{} & & & & \\
\hline Effect & se & $\mathbf{t}$ & $\mathbf{p}$ & LLCl & ULCl & c ps & c cs \\
\hline .5957 & .0896 & 6.6525 & .0000 & .4182 & .7733 & .5150 & .5391 \\
\hline Indirect effect(s) of $\mathbf{X}$ on $\mathbf{Y}$ & & & & & & \\
\hline & Effect & BootSE & BootLLCl & BootULCl & & \\
\hline Communic & .3764 & .0772 & .2312 & .5347 & &
\end{tabular}

\section{CONCLUSION AND RECOMMENDATION}

According to the results of the analysis there is a positive and strong relationship between all three variables. The strong positive relationship between exaggeration of media and communication reveals that the exaggerated messages forwarded by media has an influence on the communication by health professionals, friends and family. Consequently, the relationship between communication and generated fear is also found to be strong and positive exhibiting that the amount of communication has an influence on generating fear in minds of people. Lastly the relationship between exaggeration of media and generated fear had a strong correlation as well meaning that exaggeration is contributing to generation of fear.

Additionally, mediation analysis showed that the relationship between exaggeration of media and generation of fear is mediated by the communication by health professionals, friends and family meaning that communication plays an important role in terms of generated fear.

The research was limited to a specific sample which was the main limitation of the study. Also, the results cannot be generated because the fear generated can be influenced by other factors as well like culture, perceived quality of health system and expected outcomes of pandemic on economic situation. So future research can include other factors which may contribute the generated fear and the sample size can be expanded in order to gather more data.

Declaration of interest: The authors report no conflicts of interest.

Financial Disclosure: No financial support was received.

\section{REFERENCES}

1. World Health Organization. Rolling updates on coronavirus disease (COVID-19). 2020. Available at: https://www.who.int/emergencies/diseases/novelcoronavirus-2019/events-as-theyhappen?fbclid= IwAR1vrTHSJ3WR711YfUNuvQq9V09WL_hvTpjIOBf b5HXndxIwRpiKIwyz_4w (Accessed: 18 June 2020).

2. Yllmaz M. 20 Nisan 2020 Tarihi İtibariyle Covid-19 Virüsünün Dünyadaki Coğrafi (Kitalara ve Ülkelere Göre) Dağılımı [Geographical Distribution of Covid-19 Virus in the World (by Continents and Countries) as of 20 April 2020]. Avrasya Sosyal ve Ekonomi Araştırmaları Dergisi - Journal of Eurasian Social and Economic Studies, 2020;7(4):17-44.

3. Atac O, Cavdar S, Tokac AZ. First 100 Days of the COVID-19 Pandemic: An Evaluation of Preventive Measures Taken by Countries. Anadolu Kliniği Tıp Bilimleri Dergisi - Anatolian Clinic Journal of Medical Sciences, 2020;25(1):228-37. doi: 10.21673/anadoluklin. 733245. doi: 10.21673/anadoluklin.733245.

4. Briggs A, Burke P. Medyanın Toplumsal Tarihi [Social History of Media]. Istanbul, Turkey: Izdusum Publishing. 2004.

5. Aydeniz H. Medyayı Tanımak [Getting to Know the Media]. Istanbul, Turkey: Nakis Offset. 2012.

6. Türk GD. Demokrasinin Dördüncü Kuvveti Yeni Medya Teknolojileri [New Media Technologies, the Fourth Power of Democracy]. XVIII. Türkiye'de Internet Konferans1 - Internet Conference in Turkey. İNETD 13, pp. 55-60, 2013. doi: 10.1089/neu.2007.0375. 
7. Özdemir S. Medya Emperyalizmi ve Küreselleşme [Media Imperialism and Globalization]. Istanbul, Turkey: Timas Publishing. 1998.

8. Swingewood A. Kitle Kültürü Efsanesi [Mass Culture Legend]. Ankara, Turkey: Science and Art Publications. 1996.

9. Lang K. The Unique Perspective of Television. Mass Communication, Ed. W. Schramm, Urbana: Illinoi University Press, 1954.

10. Manheim JB. A Model of Agenda Dynamics. Annals of the International Communication Association 1987;10(1):499-516. doi: $10.1080 / 23808985.1987$. 11678659 .

11. Cereci S. Televizyonun Sosyolojik Boyutu [Sociological Dimension of Television]. Istanbul, Turkey: Sule. 1996.

12. Alemdar K, Erdogan I. Popüler Kültür ve İletişim [Popular Culture and Communication]. Ankara, Turkey: Umit Publishing. 1994.

13. Parsa S. Televizyon Haberciliği ve Kuramları [Television Journalism and Theories]. Izmir, Turkey: Ege University Faculty of Communication Publications, 1993.

14. Kulshrestha J, et al. Quantifying Search Bias: Investigating Sources of Bias for Political Searches in Social Media. Proc. ACM Conf. Comput. Support. Coop. Work. CSCW, pp. 417-432, 2017. doi: 10.1145/2998181.2998321.

15. Donmezler S. Kriminoloji [Criminology]. Istanbul, Turkey: Beta Publishing. 1994.

16. Goode E, Ben-Yehuda N. Moral Panics: The Social Construction of Deviance. Oxford: Blackwell. 1994.

17. Gerbner G. Cultivation Analysis: An Overview. Mass Communication and Society, 1998;1(3/4):175-94. doi: 10.1080/15205436.1998.9677855.
18. The Telegraph. Coronavirus: Indian man 'died by suicide' after becoming convinced he was infected. 2020. Available at: https://www.telegraph.co.uk/globalhealth/science-and-disease/coronavirusindian-mandied-suicide-becoming-convinced-infected/ (Accessed: 20 June 2020).

19. Kim AW, Nyengerai T, Mendenhall E. Evaluating the Mental Health Impacts of the COVID-19 Pandemic in Urban South Africa: Perceived Risk of COVID-19 Infection and Childhood Trauma Predict Adult Depressive Symptoms. medRxiv. 2020. doi: 10.1101/2020.06.13.20130120.

20. Arısoy A, Pepe O, Karaoglu B. Covid-19 Sürecinde Futbola Dönüş Öncesi Futbolcuların Durumluk Kaygı Düzeyleri İle Psikolojik Performansları Arasındaki İlişki Belirlenmesi: Isparta Örneği [Determining the Relationship Between State Anxiety Levels and Psychological Performance of Football Players Before Returning to Football in the Covid-19 Process: The Case of Isparta]. Yalvaç Akademi Dergisi - Yalvaç Academy Journal 2020;5(1):55-63.

21. Acar K, Mor KA, Baynaz K, Arslanoglu E. An Investigation on Anxiety States of Students in Faculty of Sport Sciences During COVID-19. International Journal of Disabilities Sports and Health Sciences 2020;3(1):6673. doi: 10.33438/ijdshs.736875.

22. Trnka R, Lorencova R. Fear, Anger, and Media-Induced Trauma During the Outbreak of Covid-19 in the Czech Republic. Psychological Trauma Theory Research Practice and Policy, 2020;12(5):546-9. doi: $10.1037 /$ tra0000675.

23. Berberoglu A. COVID-19 Pandemic in North Cyprus. Journal of Clinical and Experimental Investigations, 2020;11(4):em00742. doi: 10.5799/jcei/8213. 